\title{
La forma conveniente: destreza narrativa y pathos contenido en "El fardo" de Rubén Darío
}

\author{
Alberto Paredes ${ }^{1}$
}

Resumen. "El fardo" es un relato atípico de Rubén Darío; originalmente le causó satisfacción pero posteriormente decidió apartarse de ese modelo narrativo. El tema proviene de una realidad social inmediata. No obstante los juicios del autor, permanece como un cuento (en el sentido moderno) sumamente logrado en el que sobresale su "forma conveniente". La huella de Emile Zola, en efecto pero también la de Victor Hugo están presentes.

Palabras clave: Darío; cuento moderno; realismo y naturalismo; narratología y estilística; influencia de Emile Zola y Victor Hugo.

\section{[en] The Convenient Form: Narrative Skill and Contained Pathos in Rubén Darío's "El fardo"}

\begin{abstract}
El fardo" is an atypical Dario's short-story; he was originally satisfied by it but later on he decided not to continue writing within that narrative model. The subject sends to a direct social reality. Notwithstanding the author's judgments it stands as an achieved modern short-story notorious in its “convenient form”. Zola and Hugo's influences are visible.
\end{abstract}

Keywords: Darío; modern short-story; realism and naturalism; narratology and stylistics; Emile Zola's and Victor Hugo's influences.

Cómo citar: Paredes, A. (2020) La forma conveniente: destreza narrativa y pathos contenido en "El fardo" de Rubén Darío, en Anales de Literatua Hispanoamericana 49, 107-116.

A Evangelina, Juana y Rocío, excelentes editoras y amigas.

A diferencia de la información, el relato no se interesa en transmitir el suceso tal cual sino que, para comunicarlo al receptor, lo incorpora a la vida del narrador, haciéndolo parte de su propia experiencia. De esta forma, el narrador deja su huella, como la mano del ceramista en la jarra de barro.

W. Benjamin

Darío insiste, con arrepentimiento, en la influencia de Zola sobre su cuento "El fardo". ${ }^{2}$ Pero esto es solamente temático, más profunda me parece la ascendencia de Poe en términos de solución formal así como la de Hugo en la simpatía emocional con los personajes. Desde sus catorce años ("Primera impresión") hasta el agotamiento de sus fuerzas de escritor, Darío acudió con fiel persistencia al relato corto. "El fardo" puede jactarse de ser el más logrado de su autor, en el exigente sentido de short-story. Antes y después de este trozo de bravura cedió a una debilidad: glosar, proliferar en perífrasis y lirismos verbales y verbosos que Hawthorne, Poe y Chéjov habían sancionado. "El fardo", además, se atreve a incluir el retrato del escritor, en un ángulo lateral del conjunto, como testigo rebasado por los hechos. El narrador de un cuento moderno no

\footnotetext{
1 Facultad de Facultad de Filosofía y Letras-PASPA, Universidad Autónoma de México. México D.F. México.

Email: albertopzmx@yahoo.com

2 "En El fardo triunfa la entonces en auge escuela naturalista. Acababa de conocer algunas obras de Zola, y el reflejo fue inmediato; mas no correspondiendo tal modo a mi temperamento ni a mi fantasía, no volví a incurrir en tales desvíos” (Darío 1991: 138 y 1979: 203).
} 
está ahí para alzar la voz ante las injusticias sociales ni para dirigirles oraciones fúnebres piadosas. Ni J'accuse ni Miserere.

Por su lado, Ricardo Llopesa concluye que este cuento proviene de una experiencia inmediata de Darío a su llegada a Valparaíso: "Por esta información [circunstancias apremiantes de Darío en la capital chilena y su mudanza a Valparaíso] sabemos que 'El fardo' aunque publicado en Santiago, fue escrito en Valparaíso, en los primeros días de abril, concretamente el 2 ó 3 de dicho mes [de 1887]."(Llopesa 1994: 47) ${ }^{3}$ Lo cual permite ampliamente enmarcarlo bajo la propuesta de Benjamin. El "arrepentimiento" del "desvío" naturalista es de 1912; expresa una convicción que habrá tomado años o décadas antes, pero en 1890 parecía ampliamente satisfecho de lo que había conseguido en ese relato; es su XIII ${ }^{\mathrm{a}}$ nota a la segunda edición (1890) de Azul... : “'El fardo'. Éste es un episodio verdadero, que me fue narrado por un viejo lanchero en el muelle fiscal de Valparaíso, en el tiempo de mi empleo en la Aduana de aquel puerto. No he hecho sino darle una forma conveniente." (Darío, "El fardo" 312)

¿Cómo logró Darío, darle forma a un cuento social con figura de autor incluida? Parquedad descriptiva y aceptación de su propia circunstancia, podemos decir. El pasmo sobre los humildes deviene ficción literaria, con lo que potencializa su fuerza expresiva; del testimonio a la literatura. Es la hábil mano del ceramista, siguiendo la figura de Benjamin.

El recurso es sencillo y proverbial. El narrador, imagen del autor, dice que un viejo estibador del puerto le contó que... Sheherezade sabe de esto. Medio eficaz para eximir el suceso de las digresiones, figuras sofisticadas, observaciones morales o irónicas a las que el relato modernista fue proclive. El incipiente reportero que era Rubén Darío supo transitar hacia una dimensión más honda. Como si su instinto le hubiese susurrado: atente a contar tu historia que ya el lector pondrá lo demás. Economía y concisión. Organizar limpiamente el pequeño suceso es ingeniar su forma conveniente, en otras palabras escuchar el propio material y tramarlo con solidez. Así, a una trama eficaz le sobran los comentarios propios y ajenos. El cuento apareció originalmente el 15 de abril de 1887; su autor: veinte años cumplidos. Todo indica que estamos frente al primer cuento moderno (short-story) pleno salido de manos hispanoamericanas.

¿Qué es una forma conveniente?, ¿cuánto monta esa operación en la supuesta re-verbalización de un suceso? Se trata, recordemos, del accidente mortal sufrido por un joven estibador cuando un bulto colosal cae encima de él y le hace estallar la caja torácica. Lo escribió Darío: ese campeón del Modernismo hispanoamericano tantas veces exhibido con el sambenito de hacer una literatura de espaldas a la realidad de su entorno, literatura de escape a fuer de llenarse de salones galantes, claros de luna vaporosos y jardines pseudo-versallescos. Ello especialmente en la época que va de Azul... a Prosas profanas.

No propongo respuestas ni defensas ante quienes abriguen tales convicciones. Sólo pido que leamos el cuento; deteniéndonos y deleitándonos en la secuencia de sus párrafos, oración tras oración.

El texto se organiza en ocho segmentos separados por blancos. Podemos dejar fuera de numeración el primero, llamándolo preámbulo o entrada, y numerando siete pasajes, que incluyen el envío o salida. Es decir: el suceso ocupa los cinco segmentos centrales enmarcado por el preámbulo y salida, en los que domina la figura autoral. Lo cual es una primera evidencia de equilibrio formal.

Preámbulo. Cuatro oraciones impresionantes; a la usanza de los óleos renacentistas, parecen establecer la cuadrícula que sostendrá, invisible pero omnipresente, sutil y rigurosa, la escena capturada. Cada una de estas cuatro oraciones es de diferente tesitura que las otras, autónomas en términos de cometido; satisfacen su función respectiva sin mezclarse: horizonte; comunidad humana del muelle al final de la jornada; introducción del motivo de la futura muerte; el mar. Cito la primera. El joven de 20 años veía el horizonte:

Allá a lo lejos, en la línea como trazada con un lápiz azul, que separa las aguas y los cielos, se iba hundiendo el sol, con sus polvos de oro y sus torbellinos de chispas purpuradas, como un gran disco de hierro candente. (Darío, "El fardo" 174)

Conforme avance la narración, Darío se despojará de la suntuosa ornamentación plástica que entonces dominaba. Comparemos con el compacto motivo agorero tema de la tercera oración: "Inmóvil el enorme 
brazo de los pescantes, los jornaleros se encaminaban a las casas." En la primera oración el narrador se luce en un tour de force clásico: decir el horizonte, decir el ocaso; trasladar su hipnótica y suave plasticidad a una oración. Por su lado, la tercera, la breve descripción ominosa, podrá ser aprobada por el más exigente teorizador del cuento; al final del relato un enorme objeto inanimado descenderá violentamente sobre aquel jornalero elegido por la desgracia para no volver más a casa. Resalta por su parquedad -la única sin desarrollo plástico-; su concisión invita a una aliteración con el título: la fatalidad del fardo.

La lectura completa del párrafo muestra que la plasticidad "esteticista" está equilibrada con el objetivo narrativo: la paleta no se explaya so peso de olvidar la ubicación costumbrista del lugar; colores y líneas del poeta-narrador satisfacen la ambientación y la enunciación de locus y dramatis personce -aún no individualizados-. Estamos en la buena escuela de aquellos franceses a quienes Darío empezaba a devorar: Flaubert, los Goncourt, Zola. Sobre todo Flaubert: desviar la "prosa de arte" al servicio de narrar. ${ }^{4}$ Rigor de prosa, además, aliada con una temática realista y una actitud de escritura testimonial.

Primer segmento narrativo. "Todos los lancheros...". Es notoriamente más extenso; la máquina de contar está andando. Pálpese el vaivén medido entre párrafos descriptivos de extensión media puntuados por breves diálogos. No hay transición entre una tonalidad y la otra; el autor las contrapone y avanza con economía. Cabrera Infante habrá admirado el malabarismo de la "y" entre comas: "el viejo Tío Lucas [...] había trabajado todo el día, estaba sentado en una piedra, y, con la pipa en la boca, veía triste el mar." A cabalidad esa conjunción escoltada por comas, pues la justifican dos proposiciones circunstanciales en formación de quiasmo. ${ }^{5}$ El más exigente árbitro de esa ciencia poco atendida, el estilo en la puntuación, no podría enderezar la menor objeción sintáctica.

Abruptamente caemos en la cuenta de que no estamos en los terrenos de la tercera persona narrativa: "esa charla agradable y suelta que me place entablar con los bravos hombres toscos". "Yo veía con cariño..." 6 Convoquemos a un tiempo a Montaigne y al realismo o naturalismo a la latinoamericana. Al final de sus Essais, Montaigne declara, no sin inmortal coquetería: «n'ayant fourny de mien que le filet à les lier » (III, 12.) Tal función cumple a cabalidad el "yo" de este relato que aprovecha los registros de la crónica y la ficción. Los "cuentos en prosa" ocupan grosso modo dos tercios del volumen total en Azul... La temática y las soluciones formales varían, dentro de cierto rango no demasiado amplio; algunos están en tercera persona y los hay en primera. Sostengo que invariablemente están mirados desde una misma perspectiva intelectiva: un yo que observa desde el resguardo de su media distancia. ${ }^{7}$ Azul... en efecto, lejos de ser yuxtaposición de piezas en verso y prosa es un libro orgánico gracias al yo como sutil hilo que los une.

Recordemos algunas declaraciones de Ángel Rama en su prólogo para Ayacucho: "Hacia donde mire, el poeta [recién llegado a Santiago y Valparaíso] registra el desorden del universo", "observa la contradicción desde un ángulo moral, más que social" y "Su arte se sostiene sobre la agudeza de la paradoja". (Rama, "Prólogo": XX y XXI) El relato lo declara con exactitud y "sin literatura", por así decirlo: asienta "yo veía", con la simpatía de quien constata y simpatiza, manteniendo cierta distancia: "con cariño".

El pasaje ofrece una alabanza de tipo rousseauniana y aun horaciana, beatus ille, "los bravos hombres toscos que viven la vida del trabajo fortificante, la que da la buena salud y la fuerza del músculo, y se nutre con el grano del poroto y la sangre hirviente de la viña". La diestra prosa plástica nos lleva de esta paz de los humildes a su reverso no escatimado: "-Sí, patrón ¡hace dos años que se me murió!" (175)

Llamemos "patetismo social" la perspectiva de Darío frente al panorama colectivo que descubre sobre las primeras manifestaciones hispanoamericanas de la explotación laboral industrial. Ciertamente, no hay de

4 "Y lo difícil para mí [habla Eduardo Poirier] era despertarlo por las mañanas, para que llegase con puntualidad a su empleo, después de haberse llevado casi toda la noche devorando en el lecho y mascullando en alta voz [...] alguna novela de Flaubert, de Goncourt y de Zola, o entregado al delectante estudio de sus maestros favoritos: Hugo, Verlaine, Poe, Walt Whitman” (Raúl Silva Castro, Rubén Darío a los veinte años, Santiago de Chile, Andrés Bello, 1966, p. 187; cito por Martínez, 1994: 20).

5 ¿Será Cabrera Infante el único estilista y estudioso de literatura que ha alabado y se ha halagado con el recurso de ", y,”? Véanse en particular sus esmerados Exorcismos de esti(l)o, libro dedicado "a las comas, alegres, diversas, múltiples, minuciosas, salvadoras pero modestas..." (Barcelona: Seix Barral, 1976). Distraigo al lector con la p. 252 de GCI: "No hay frase famosa, ni última ni primera, que me levante el ánimo tanto como aquella en que puedo ver una $y$ entre dos comas, así: pieles y pies, y, como era de esperar, así: [...]"

Me entristece que don Ernesto Mejía Sánchez haya suprimido la primera coma (Darío 1950 y 1983: 102). Por su lado la Revista de Artes y Letras ostenta, en la p. 114, el artificio que ocupa estas líneas. (Si el lector no puede consultar el texto directamente, existe una reproducción en línea: http://www.archive.org/stream/revistadeartesyl09sampuoft/revistadeartesyl09sampuoft_djvu.txt )

${ }^{6}$ Dispenso al lector del tradicional y paternalista "el subrayado es mío”, por parte del crítico: Darío escribe lo suficientemente claro como para que no le subrayemos nada.

${ }^{7}$ Para mi noción de autor en primera persona, cf. Las voces del relato. 
dónde forzar textos como "La canción del oro" y nuestro "El fardo" para proponer un Darío comprometido, militante, de obra acusatoria y sólidamente engagé. Volveremos sobre esto en el desenlace.

Obsérvese, antes de avanzar, el esmerado párrafo-oración final de la sección; el narrador había guardado hasta este punto el primer periodo sintáctico en que el mar y un sujeto humano convivan y se integren, al tiempo que se expanden plásticamente. Los recursos del tejido gramatical son un polisíndeton sostenido apoyado en comas; una red que fija al narrador en posición de escucha del tío Lucas:

Y todo me lo refirió, al comenzar aquella noche, mientras las olas se cubrían de brumas y la ciudad encendía sus luces; él, en la piedra que le servía de asiento, después de apagar su negra pipa y de colocársela en la oreja, y de estirar y cruzar sus piernas flacas y musculosas, cubiertas por los sucios pantalones arremangados hasta el tobillo. (Darío, "El fardo" 175-176)

Subrayemos, junto con la habilidad sintáctica, la cadencia con que enhebra los elementos; perciba el lector que gracias a esa fluidez brotan los temas, pues todo es tratado como tema compositivo: piedra de asiento, negra pipa, oleaje contra la ciudad, fisonomía y vestuario característicos.

Segundo segmento narrativo. "El muchacho era muy honrado..." El narrador escucha y recuenta mediante el discurso indirecto libre. Relato dentro del relato. Acaso sea éste otro filón orientalista de Darío. El siglo XIX continuaba la popularidad del epónimo libro de libros que cuenta que se cuenta: Sir Richard Burton vio publicadas sus esforzadas The Thousand Nights and a Night en 1885 (10 vols. y 6 suplementarios entre 1886-88). ${ }^{8}$ Mediante el artilugio, Darío permite a su yo narrativo libertad de léxico y de giros sintácticos; lo mismo habrá vocablos coloquiales como "grandecito" y "cuartucho" que la magnética expresión "zambras de echacorvería" para hablar del escándalo nocturno de prostitutas y malvivientes. ${ }^{9}$

Empieza con este segmento una secuencia de tres apartados en el distendido tiempo del copretérito o pasado indefinido; acciones continuas para hacer la acuarela de los oficios mezclados de estibador y pescador. Propongo leer con ironía y grano de sal el "patetismo social" del autor cuando el primer párrafo cierra, exclamativamente, con fatalista moraleja adelantada: "ipero los miserables no deben aprender a leer cuando se llora de hambre en el cuartucho!". Se nos despliega en ágil apunte el tiempo largo que va de la infancia a la adolescencia del muchacho (innominado: hasta el final innominado); el acordeón de la prosa se sintoniza: el mayor de todos los párrafos de "El fardo" para ese apunte, que un Roberto Arlt podría llamar "aguafuerte porteña", puntuado y cercado por la contención de dos párrafos-oración informativos y lacónicos. En efecto, cabe toda la "melodía de arrabal" entre "El tío Lucas era casado, tenía muchos hijos." Y: "Luego, llegaron después sus quince años." Dentro del amplio párrafo, la riqueza de los recursos sonoros y lexicales es innegable; amén de la destreza en el manejo sintáctico rebosante de paralelismos, contrastes e inversiones en la construcción de las frases y proposiciones gramaticales. ${ }^{10}$

Cómo no pensar, además, en el inminente tango-canción, y en la hagiografía laica y "pietista" de unas décadas después con las que otra industria nueva, el cine mexicano en blanco y negro, inundaría de claroscuros y sepias melodramáticos cabezas y corazones de nuestras "Ínclitas razas ubérrimas, sangre de Hispania fecunda" tan ávidas del folletín conmiserativo sobre Nosotros los pobres (Ismael Rodríguez, 1948; el verso de Darío en la "Salutación del optimista", Cantos de vida y esperanza, 1905). ${ }^{11}$

${ }^{8}$ ¿Se sabe qué versión habrá frecuentado Darío?, ¿en qué lengua?; si no fue en español, ¿la de Antoine Galland, 1704-17?; ¿la de E.W. Lane, 18381840 -"eruditísima” y puritana, según Borges-?, ¿la de John Payne, 1882-1884? ¿Habrá tenido acceso tan prematuramente a la admirable de Burton, aparecida en Londres apenas en 1885? Pues "en castellano", como entonces se decía, es flagrantemente tardía su aparición.

${ }^{9}$ Ignoro si la expresión es frase lexicalizada, por ejemplo, en Chile o quizás precisamente en el puerto de Valparaíso finisecular; ¿Darío oyó y usó los vocablos ayuntados o es el responsable del sonoro y expresivo maridaje? Corominas y Pascual en su Diccionario crítico etimológico castellano e hispánico consignan: “'zambra', orquesta morisca, baile de moros, fiesta morisca con música y algazara, del árabe zamr 'instrumentos musicales'. 1 1a doctrina: 1586, Góngora." (1984, VI: 61). "La frase echar el cuervo significaría primitivamente 'ofrecer algo cuyos efectos se prometen y nunca se realizan', 'ganar dinero deshonestamente prometiendo cosas que no se cumplirán [...] Más que el de hipocresía, el matiz típico de la idea es el del sujeto ridículo y despreciable aunque impostor: el que 'echa cuervos', que no vuelven nunca ni pueden volver." (1991, II: 543). Volviendo al joven Rubén Darío: en 1885 ya tenía conciencia del primer vocablo de la llamativa frase: "Un día, el harén se agita/ en fiestas en zambra y ruido;/ es que el Sultán ha elegido/ a Zela, su favorita.” Se trata, por supuesto, del poema “Alí -oriental-” de Epístolas y poemas.

${ }^{10}$ Raimundo Lida, en su estudio preliminar de los Cuentos completos, dice, a propósito de "El rey burgués": "la prosa [...] se organiza en paralelismos y simetrías" (11) y su entusiasmo le hace alabar: "En versículos -lluvia de brillantes rasgos pictóricos- se deshacen a menudo los párrafos de 'El rey burgués'." (12)

${ }^{11}$ Fechas de nuestra educación sentimental: el tango ya reconocible como género musical proviene de fines del siglo XIX; el tango-canción, con su magnífica mitología arrabalera porteña es de los años veinte del siglo XX, el surgimiento de Gardel y Le Pera, por supuesto. Anotemos que, en 
Tercer segmento narrativo. "El tío Lucas había logrado..." Lograr, "tras mil privaciones, comprar una canoa. Se hizo pescador." Percibimos ya que el relato, indirecto en sus narradores, observa cronología lineal. Siguen los recursos anafóricos, rítmicos, el compás de extensiones a que nuestro cuentista de veinte años es tan sensible. Y cauteloso: nada, ni en lo temático-anecdótico ni en la invención de la "forma conveniente" es abusivo. El cuento no tendrá una fuerte consciencia social sobre los oprimidos pero tampoco cede al chantaje compasivo ni se solaza en su pirotecnia verbal. En ésta, su primera madurez, Darío ya está comprendiendo que la felix forma se debe a la armonía y equilibrio de los componentes.

La escena de la canoa es un bautizo salobre, no de fuego sino de tormenta y temporal, para el hijo e incluso para el viejo. Se narra una derrota marina. "Pesca y todo se fue al agua, y se pensó en librar el pellejo." A sus quince años, el muchacho cumple su rito iniciático, de carácter laboral, en esbozo costumbrista: las manos vacías le entregan su tesoro y destino: "Después, ya son ambos lancheros." Como se ve, el narrador indirecto, el paseante con oídos, ha llegado a su punto máximo de desaparición; una serie de habilidades verbales le asisten para ello. El desarrollo de este segmento sucede a partir del verbo "haber" y del "se", un "se" inicialmente pronominal, ambos recursos van desdibujando al narrador, desaparece su silueta del frente de escena, y la gramática desemboca en el riguroso "se" impersonal para concluir el pasaje con una enunciación objetiva sin sujeto: "Después, ya son ambos lancheros." Cuando la narración termine, el narrador regresará ostentosamente su primera persona frente al lector, aturdiéndole, quebrándole en añicos "la ilusión realista"; pero ahora, arteramente, está en su nadir. ¿Vemos alguien en este segmento que a sí mismo se profiere desde el fantasma de la tercera persona narrativa?

Cuarto segmento narrativo. “iSí!, lancheros...” Será el último del fresco en pasado continuo. Éste, como los dos anteriores, tiene un objetivo propio y exclusivo. Digamos: exaltada loa en prosa a los pescadores artesanales. Volvemos al tono del beatus ille de cuando el narrador se topa con el tío Lucas. Nuestro artista de la prosa saca un as nuevo: después de los veloces golpetazos de las oraciones-párrafo y del aire de los párrafos extensos, el reto de un vasto párrafo oración. Un solo desarrollo sintáctico-semántico, tan trabado y rico en paralelismos y autorreferencialidad, que el segundo "isí!, lancheros" equivale al tenor que ha descendido al fondo de sus pulmones, esforzado él, y, en técnica de respiración continua, desde ese suelo se impulsa para volver a lanzarse en pos de su cenit virtuoso. ${ }^{12}$ No me parece fortuito que el tema sobre el que descansa este do de pecho sea un típico tópico de exaltación: la vida marina. Pensemos tan sólo en la "Canción del pirata" de Espronceda (1840), y, después de Darío, en la "Ode marítima" de Álvaro de Campos (1915) e inevitablemente, ya que la pesca se pierde, The Old Man and the Sea (Hemingway, 1952).

No basta con eso: al vuelo de la prosa, en un periodo sostenido, el narrador se impone dificultades. Es un Ícaro que deliberadamente se lastra. Inversión del periodo oracional: primero una serie de proposiciones secundarias, subordinadas que despliegan la predicación, las tareas de estos hombres de mar -en proposiciones circunstanciales, gerundivas con efecto iterativo- para llegar al centro apretado del periodo: "isí!, lancheros", y desembocar, impulsados por el presto de la sintaxis, en el sujeto dual, surtidor de una nueva cadenza de paralelismos: "el viejo y el muchacho, el padre y el hijo; ambos a horcajadas sobre un cajón, ambos forcejeando, ambos ganando su jornal, para ellos y para sus queridas sanguijuelas del conventillo". Todo el párrafo es lujo de aliteraciones y cadencia de prosa, de trama sintáctica, de expresión de la exaltación. Es el himno de júbilo de los más humildes, un cuento que fuese oda, evocando la grandiosidad de Les Travailleurs de la mer (1866), de Victor Hugo, tan admirado por Darío. ${ }^{13}$

El tenor llega a su silencio momentáneo, respira, y, ya en su potencia media, ataca los siguientes dos párrafos que, sin embargo, no retroceden demasiado estilísticamente: el primero es un párrafo-oración de

coincidencia con el apogeo modernista, Gerardo Matos Rodríguez compuso entre 1915 y 1916 la música de "La cumparsita"; por su lado, la letra célebre es de 1924 (Pascual Contursi y Maroni), inmortalizada inmediatamente por El Morocho del Abasto.

Un aporte fundamental de México al melodrama: Santa, de Federico Gamboa es de 1903, y en 1931 vino la consagración fílmica de Antonio Moreno, con Lupita Tovar (aunque hubo una primera versión silente en 1918, de Luis G. Peredo con Elena Sánchez Valenzuela).

${ }^{12}$ Mejía Sánchez en su edición de los Cuentos completos opta por dos oraciones, empezando la segunda con el segundo “¡Sí! Lancheros;” Si bien no puede haber certeza de hasta qué punto los editores de Artes y Letras hayan respetado en todos sus detalles la escritura y puntuación darianas, opto por seguir a Martínez en su edición de Cátedra. Pues finalmente, suena improbable que haya sido algún cajista o tipógrafo el responsable del tipo de sofisticaciones que Mejía Sánchez aplana y normaliza.

${ }^{13}$ La historia de ese gran fresco narrativo de Hugo es muy otra, pero no dejan de atraer ciertas coincidencias temáticas. Hugo y el joven Darío privilegian como protagonistas los humildes, se alaba la dignidad de su trabajo en contacto con las fuerzas de la naturaleza. Y en ambos casos se cuenta una desdicha y el sacrificio de un joven de noble espíritu. En Hugo se trata del memorable Gilliatt que acomete una empresa digna de Hércules, bajo la promesa de la mano de la hija del patrón; Gilliatt vuelve a tierra victorioso... para resignarse a que la bella Déruchette se case con otro. El desenlace habrá seducido a Darío - si es que lo conoció-: Gilliatt propicia las bodas secretas de los enamorados y los asiste en su fuga. Al final, nuevo paralelismo con el breve relato que nos ocupa: el tío Lucas conversa con el narrador desde un promontorio: "estaba sentado en una piedra, y, con la pipa en la boca, veía triste el mar" mientas hace su relato. Por su cuenta, Gilliatt ha acompañado a los enamorados a huir por el mar; se sienta, igualmente, en un promontorio; es la marea alta; permanece inmóvil mirando el horizonte mientras las olas cobran su joven vida. 
extensión adecuada (cuatro líneas, digamos), que esboza la rutina diaria; el segundo contrasta por ser un entrechocar y suceder de proposiciones rápidas; algunas a cuenta del transparente narrador que sólo reporta, sin comentar ni adornar gratuitamente, y las otras son admoniciones fuertes, claras, escuetas, del vigilante tío Lucas al primogénito dilecto.

No dudo en decir que éste es el punto más virtuoso del relato; una densa y compleja trama sintáctica sosteniendo impecablemente un despliegue estilístico sin par. Ornamentación en el más alto sentido musical: momento en que el desarrollo no podrá hacerse llanamente sino en el lance virtuoso, imposible ir a ras de tierra. Esto es prosa, esto es arte. Ícaro, por esta vez, voló indemne, y desciende con suavidad al blanco que lo acoge al final de este inolvidable forte, su gran aria de bravura.

Quinto segmento narrativo. "Hasta que un día..." Riguroso, nuestro autor ejerce ahora lo que ya anunció: a la alabanza de la buena vida de los humildes, la espada fatal del destino (que podría melodramatizar algún letrista de tango o bolero). Tema del anagke, imán poderoso para Hugo y su discípulo Darío, amantes de la libertad. Pero el joven Darío es parco cuando libera las parcas sobre sus miserables, tan huguescos como zolianos. ${ }^{14}$ Empieza por no acudir a la falacia patética, teorizada por el sabio Ruskin: "Era un bello día de luz clara, de sol de oro." El continuum de los tres segmentos anteriores, esperanzadores para el tío Lucas, conduce, en la linealidad irreversible de la trama, a la orfandad; he aquí una sagaz explotación del menos imaginativo de los tiempos narrativos: avanzar en el cuento es ir hacia la fatalidad. "Hasta que un día el tío Lucas no pudo moverse de la cama, porque el reumatismo le hinchaba las coyunturas y le taladraba los huesos." Nótese la contención de la (no) adjetivación sentimental. Hemos entrado en un pretérito finito y único; doble orfandad: el hijo partió a la faena solo y dejará al padre sin su primogénito y mano de obra familiar. Después de la enunciación del día luminoso, la más espléndida aliteración o cadenza en /r/ del cuento: "En el muelle rodaban los carros sobre sus rieles, crujían las poleas, chocaban las cadenas. Era la gran confusión del trabajo que da vértigo, el son del hierro; traqueteos por doquiera"; para rematar el parrafito con una imagen que parece metáfora pero engañosamente pues se ciñe a su doble literalidad: “... por doquiera, y el viento pasando por el bosque de árboles y jarcias de los navíos en grupo". En efecto, se llama arboladura "el conjunto de palos, vergas y masteleros de un buque de vela" (Amich, Diccionario marítimo: 41), y, por extensión, de navíos con otro sistema de propulsión. Imagen pues, cristalizada con dos literalidades: las naves tienen arboladura, es decir 'bosque' y sobre ella como sobre los conjuntos forestales, bien puede soplar Noto, el hostil Bóreas o cualquiera de sus congéneres. (Abril, en el hemisferio sur es el inicio del otoño.)

Está empezando el día, con él, la acción medular del relato. Tiempo aristotélico. Si esto es un cuento moderno o short-story, en la línea de Poe y Hawthorne, a pesar de la doble acción de narrar (el tío Lucas al narrador y él a nosotros), la "acción única y final" del cuento, ${ }^{15}$ de esta pieza escénica en seis actos, preámbulo y coda, será la muerte del muchacho sin nombre, al final de la jornada, en los sentidos laboral y escénico. Reparemos que nuestro relato se concentra en un fin de jornada... que se desdobla: en primer lugar hemos sabido de la de un empleado aduanal sin relieve, cuando al deambular se entretiene a imaginar frases y metáforas para el horizonte poniente, y de súbito lo sorprende la "charla agradable y suelta" de un viejo marino, quien le cuenta el final de la joven vida de "su muchacho" cuando concluye un intenso jornal de estibadores. Este segmento, naturalmente, sostiene el equilibrio entre la prosa de arte y el decurso narrativo; en este caso, Darío se muestra tan bueno para hilar imágenes como para no perder la guía de la lengua descriptiva, y avanza con nitidez a lo largo de los sucesos y escenarios.

Párrafo fundamental es el siguiente en el que asistimos a la descarga de los bultos del barco; regreso a la imagen inicial, agorera, de la plomada del destino: "la larga cadena que remata en un garfio, sonando como una matraca al correr con la roldana"; nuevamente la música crujiente de la aliteración en / $\mathrm{r} /$ sostenida incrementa la fusión de imágenes que al mismo tiempo son sonoras y visuales, para culminar en una magnética visión de sincretismo sensorial y simbólico: “y entonces éstos [los fardos] subían a la manera de un pez en un anzuelo, o del plomo en una sonda, ya quietos, ya agitándose de un lado para otro, como un

\footnotetext{
${ }^{14}$ Arturo Marasso propone un modelo para nuestro cuento: "Les pauvres gens” de La Légende des siècles, XIII, iii (Rubén Darío y su creación poética, 356: "No era necesario Zola para escribir 'El fardo', donde hay 'su poquito de Coppée' -si empleamos una frase de Darío que innegablemente se refiere a este cuento-, bastaban o Coppée o el Hugo de "Les pauvres gens "'). No obstante el mismo Marasso ha de aceptar la indicación del propio Darío, si bien hay impronta de Hugo y Coppée, "la influencia de Zola es más vigorosa en Azul...", ibid.

Marasso envía a: "LII. LES PAUVRES GENS": La Légende des siècles ; Première série, 1859 ; ensemble final : 1883.

${ }^{15}$ Me permito remitir: Alberto Paredes, Las voces del relato.
} 
badajo, en el vacío". Regresa la única escena efectiva de pesca, aquella en que se pierde u ofrenda el producto en el sacrificio iniciático de pubertad; más adelante el pez gigante que es el fardo con su mínimo anzuelo se transformará en un perro dejando vacío su collar, o mejor dicho: veamos el vacío del collar sin su perro. La secuencia ha empezado con la ausencia del padre, que comporta el silencio de sus consejos; la última vez que el muchacho ha escuchado a su padre, en el cierre del segmento anterior, fue para atender sus vigilantes llamados: “-iMuchacho, que te rompes la cabeza! ¡Que te coge la mano el chicote!”

Tema del vacío y del silencio; ésa es una sola cara de la moneda, con dual efigie; la otra... la otra será rotunda y desconcertante en su hieratismo. Pasemos, por lo pronto, de ese silencio al mudo redoble de la muerte anunciada; oigamos el paso de la muerte, "como un badajo, en el vacío".

¿El contenido del fardo fatal? "Era algo como todos los prosaísmos de la importación [...] linones y percales", es decir las telas finas que vemos lucir en varios de los otros "cuentos en prosa" del mismo libro, aquellos que engalanan a damiselas y pretendientes pseudo-aristocráticos. Las refistolerías de la pretenciosa clase alta latinoamericana se comunican impasiblemente con los bajos fondos de las zambras de echacorvería.

Sexto segmento narrativo. "Sólo él faltaba." Segunda y última parte de la escena central. El joven cuentista ha percibido que en este drama las unidades cuentan; en consecuencia aborda el clímax anunciándolo lacónicamente; cero adjetivos y ornamentación descriptiva. Gradación de tiempos verbales: el íncipit en copretérito que justamente expresa el remanente; toma la estafeta el gerundio del suspense narrativo: "Bajó la cadena danzando en el aire." Nótese la bien trabada unidad oracional entre el verbo en pretérito directo y el gerundio que danza... Es el instante decisivo de la anagke -como rotula un poema del mismo libro: el sacrificio (inútil) de los inocentes. Desembocamos en el pretérito de indicativo, es el desenlace que se cumple en un parpadeo, referido con precisión y dinamismo por el narrador (que es el tío Lucas, que es el yo dariano): "El fardo, el grueso fardo, se zafó del lazo ...", aquí se llega a la imagen análoga al "pez en un anzuelo": “... se zafó del lazo, como de un collar holgado saca un perro la cabeza”. La alternancia de las dos formas de pretérito arma el desenlace; el cierre de este párrafo consuma el accidente en pretérito perfecto, irrevocable: "y cayó sobre el hijo del tío Lucas, que entre el filo de la lancha y el gran bulto, quedó con los riñones rotos, el espinazo desencajado y echando sangre negra por la boca". Ahora el gerundio tiene la fúnebre misión de volver vívido el instante de la agonía por estallamiento de la caja torácica. Veamos esa bocanada de sangre, es Homero, sus héroes exhalando el ánima tal como describe la clínica médica, con los pulmones estallando, volcando el último escupitajo de sangre venosa consumida y ya sin oxígeno. La vida ha partido.

Este segmento se ha iniciado con golpes oracionales cortos (stacatti, podría decir el poeta Darío) que dejan al muchacho al borde de un heroísmo que se revela martirio; el momento mismo del accidente y su pasmo inmediato vuelven a recibir un tratamiento holgado, no por abundancia de adjetivos y adverbios, sino por ofrecer el detalle de la circunstancia del hecho funesto. La plasticidad al servicio de "la Reina invencible, la bella inviolada: / la Muerte", según dirá diez años después en "La página blanca" (Prosas profanas, 1896).

Recordemos que el autor contaba 20 años cuando el cuento apareció originalmente. Omitió, sagazmente, datos clave para individualizar "al muchacho": ignoramos su nombre y sus edades son vagas. Sabemos que ha cruzado una enfermedad de alto riesgo, probablemente en el paso de la pubertad. "Luego, llegaron después sus quince años.” (Frase final del segundo segmento narrativo.) ¿Cuánto tiempo pasó antes del día del fardo fatal? Lo ignoramos. Seguramente portaba secuelas de su crisis de salud en edad de crecimiento. No obstante, al momento de los hechos era ya "un mocetón". Antes y después de la escritura del cuento, Darío experimentó inestabilidad económica, pero no al grado de haber tenido nunca que emplearse en labores físicas pagadas por jornal... ¿Cuánto habrá sentido, consciente o inconscientemente, que un delgado filo social separaba apenas el estatus del escritor de aquel de su personaje?

Perfecta inclemencia con el muchacho. No sólo debida al fardo que lo destroza en aquel segundo puntual tiempo unánime en el que se conjugan las precarias o nulas medidas de seguridad laboral y la espada de la desgracia proveedora de una fatalidad que bien podemos imaginar ilustrada en una estampa de sepias profundos y cremas deslavados; es el puno, el nudo narrativo, en que coinciden sin tacha todos los que cuentan el cuento de su muerte: concilio de verdugos que asfixia la individualidad del personaje desde el pocillo del tintero. En efecto, ni el flâneur de Valparaíso ni su padre resignado ni el autor mismo han cedido la menor gota para dedicar siquiera un par de rápidas líneas a "los generales" caracterológicos, de suerte que el lector contemplara ante sí un rostro, un arco peculiar de cejas, un rictus de labios, timbre de voz, un nombre familiar o un modo característico de caminar por entre los baresuchos del puerto a los que seguramente nunca habrá ido a ofrendar su castidad o su sobriedad. Nada. Normalmente el que el personaje focal no esté individualizado es un error elemental, atroz, en la narrativa. Pero no en este caso. El 
primogénito del oscuro y silente tío Lucas es una forma de la nada. Una figura social al mismo tiempo peculiar (lo individualiza sobre todo su muerte) y genérica, estadística incluso. Más allá de la admiración o rechazo que se profese a Darío, convéngase que esa anonimia es un arriesgado lance (¿deliberado, instintivo?) del joven escritor. Desde la presentación, sabemos que el jovenzuelo es un ausente. Actúa en aras de la exhalación presagiada; la cual se consuma en un breve pasar de páginas. Un caso entre verdad y fabulación que los lectores del 15 de abril de 1887 de la Revista de Artes y Letras habrán conocido mientras hojeaban su ejemplar; para que todos nosotros, sus sucesores, calcemos sus gafas mediante esmeradas ediciones anotadas. ¿Cuánta filología tolera la carne de la desdicha?

Hablando de nadas y narradores, ¿dónde quedaron sus pobres hermanitos? Dos frases: "En el oficio [murió el hermano mayor], por darnos de comer a todos; a mi mujer, a los chiquitos y a mí, patrón, que entonces me hallaba enfermo." La segunda: "ambos ganando su jornal, para ellos y para sus queridas sanguijuelas del conventillo". Me imagino que los cautelosos letristas de tangos, boleros y películas de arrabal y quintos patios desaprobarían la claridad con la que el tío Lucas, el flâneur que "veía con cariño" y el autor mismo subrayan que los chiquitos son una tierna obligación, un fardo nutricio. Además: ¿a cuál de las tres instancias narrativas reclamar airadamente el olvido en el que se les abandona literariamente? En efecto, fuera de esas dos menciones se vuelven otro más de los círculos vacíos que construyen el relato. Digamos que no procede el reclamo: el joven autor es osado en sus empresas; lo desdibujado del primogénito y de sus hermanitos tiene efectos favorables de parquedad y antimelodramatización. Es parte de la impune y certera "cachaza" que ha dado la "forma conveniente" a los fardos de "El fardo".

Envío y final del relato. "Me despedí del viejo lanchero..." Leamos la salida, nuevo párrafo uni-oracional:

Me despedí del viejo lanchero, y a pasos elásticos dejé el muelle, tomando el camino de la casa, y haciendo filosofía con toda la cachaza de un poeta, en tanto que una brisa glacial que venía de mar afuera pellizcaba tenazmente las narices y las orejas. (Darío, "El fardo" 180)

No creo casual que al verbo nuclear, de nuevo en pretérito finito ("dejé el muelle"), sucedan dos proposiciones verbales de gerundio ("tomando...", "haciendo..."), las cuales cobran relieve en la escena final del texto narrativo y de hecho están impulsando el largo giro del sintagma adverbial conclusivo que transcurre continuo, aligerado de puntuación hasta llegar al punto final definitivo. Estamos en un cuento en que los silencios y hiatos rinden sus beneficios. (Lo cual es una exigencia del short-story moderno pero algo muy ajeno a los hábitos narrativos de los modernistas.) Volvemos, en buena lección clásica, a la situación y personaje de partida; el yo narrativo, ese (ijoven?) hombre solo, quien al momento del cierre incurre en la elipsis de su informante, el tío Lucas, suavemente desvanecido en un fin de jornada que, esta vez, dice que las "opacidades de la neblina" usuales son el humo inasible en que se esfuman las esperas y esperanzas, y el destino de los humildes. El narrador mira, escucha, atestigua y no actúa. Obviamente no pudo actuar en el momento del accidente, al cual no asistió, pero tampoco interactúa con el viejo Lucas y su familia, una vez que sostuvo esa charla. Detengámonos conforme se aleja: aceptemos la honestidad de la mirada dariana que exhibe sus límites. No es que atrapemos su alter ego narrativo in flagranti indiferencia; es la cámara inclemente del relato quien nos pide mirarlo mirando. ¿Sólo él se aleja sin inmutarse o el lector también?

El narrador pone frente a nosotros su sorna y casi podemos atribuirle un encogerse de hombros. Ya le refirieron un accidente mortal y ahora el objetivo es protegerse del friecillo nocturno otoñal en el puerto vacío. No será el lector quien lo señale como "desinvolucrado" o "indiferente", se basta a sí mismo para ello, pues su artilugio de ironía se dirige tanto contra el código sentimental de barriada como contra su propia impersonación literaria. "Un final deliberadamente trivializado, que contrasta con la sobria crudeza de las páginas anteriores", comenta Lida (19) en su prólogo.

El narrador de Darío aparece al inicio para dar pie al texto, durante el cual hace mutis, y vuelve para cerrarlo. Es decir, asistimos al proceso señalado por Benjamin en nuestro epígrafe: la transformación de la noticia en experiencia. Testimonio discreto pero claro "yo acuso" personal: yo me acuso de pertenecer a la sociedad que crea tales víctimas laborales. Sé que esto existe y que lo dejamos pasar. Enteraos, suscriptores santiaguinos privilegiados de Artes y Letras y de La Época (donde se reprodujo quince días después). Es efectivamente el camino que llevará a Zola, una década más tarde, a la culminación del J'accuse en el affaire Dreyfus, originalmente aparecido en L'Aurore el 13 de enero de 1898. Darío abandonó la senda de la narrativa social militante; lo hizo conscientemente; su gloria literaria es otra mas no menor que la del inmortal francés. A menudo las novelas de Zola incurren en parrafadas de patetismo social que este ejercicio juvenil supo eludir. 
En "Un retrato de Watteau" del mismo Azul... leemos y no podemos dejar de enlazar: "estáis viendo". Para eso sirven el narrador y la literatura. Ver y hacer ver. Desde el ver expositivo de vocación neutra (el "realismo" flaubertiano) hasta el ver que exhibe pruebas incriminando (naturalismo de Zola). ${ }^{16}$ De modo que en los primerísimos días de su desempeño como empleado aduanal en Valparaíso prestó ojos y oídos a muertes laborales como la de ese joven personaje sin nombre. No, no hay dimensión social, colectiva ni mucho menos gremial en "El fardo", ni, en principio, en Darío. Hay la destreza de uno de nuestros mayores poetas y prosistas modernos para resaltar casos individuales. La explotación de que esos actores sociales son sujeto, al ser visualizada desde tal "cariño" individualizante, ingresa al marco de una suerte de compasión por los oprimidos (escuela de Victor Hugo). El escritor, qué duda cabe, retiene el texto, es parquísimo en adjetivaciones y adverbiaciones, sobre todo de carácter moral-acusatorio. ¿En qué medida por olfato antimelodramático y en cuál por exigencias estilísticas? El resultado es uno y el mismo: no resbala en lo lacrimoso y deja que su pluma se expanda en la plasticidad y eficiencia de consumar un relato llevándolo a su perfección posible. En efecto, se trata de contener: "No he hecho sino darle una forma conveniente." La forma dice y carga de potencia el dispositivo narrativo.

No obstante, no quiero demeritar la enjundia de quienes han señalado el carácter inaugural de este cuento dariano en los terrenos de la narrativa naturalista y testimonial; en particular Ricardo Llopesa y Fidel Coloma: “"El fardo' es el primer texto literario del naturalismo latinoamericano [...] como apunta Fidel Coloma, [es] el primer relato de la literatura testimonial hispánica” (Llopesa: 54-55).

En las fábulas antiguas, en verso y prosa, el relato privilegiaba un acontecimiento fuera de lo común, fuese desdicha o proeza, elevándolo a la categoría de exempla, para concluir la operación retórica (es decir la utilización extraliteraria de la anécdota) con su lección en glosa explícita, la moraleja; recurso al que a veces con fortuna y muchas otras con desdoro han acudido los modernos narradores sociales, los naturalistas a la cabeza y posteriormente el "realismo socialista" y los escritores contemporáneos que se comprometen con las causas urgentes; autores que frecuentemente nos dicen: no basta con exponer, hay que comentar, acusar, teorizar, sermonear, militar... Este joven y ambicioso escritor y reportero de veinte años supo esconder la mano de la moralina; fábula con antimoraleja: -ya oí, ahora me voy a casa, que el frío arrecia, dice la cachaza del flâneur de Valparaíso.

No será exagerado sugerir que logros como este del joven Darío recién llegado a su segunda década vital serán parte pionera que abrirá horizontes, andando el tiempo, a nuestros mejores narradores sociales, los Arguedas, Asturias y Revueltas. La pluma, el estilete verbal, estaba pronta para enfrentarse a esos retos, a un tiempo sociales y literarios. ${ }^{17}$

\section{Referencias bibliográficas}

Amich, Julián (1956). Diccionario marítimo. Barcelona: Juventud.

Benjamin, Walter (2002) [1979]. Charles Baudelaire. Tr. y ed. Jean Lacoste. Paris: Éditions Payot, p. 154. ${ }^{18}$

Coloma González, Fidel (1988), "Lo revolucionario en Azul... de Rubén Darío", Boletín nicaragüense de bibliografía y documentación, $\mathrm{n}^{\mathrm{0}} 56$ (febrero-abril 1988): 111-124. ${ }^{19}$

Darío, Rubén (1977). Poesía. Ed. Ernesto Mejía Sánchez, pról. Ángel Rama, pról. y cron. Julio Valle-Castillo. Caracas: Biblioteca Ayacucho.

Darío, Rubén (1979). Páginas escogidas. Ed. Ricardo Gullón. Madrid: Cátedra, 1979.20

Darío, Rubén (1983) [1950]. Cuentos completos. Ed. de Ernesto Mejía Sánchez. México: FCE.

Darío, Rubén (1991). Historia de mis libros. Buenos Aires, La Nación, 1912, en La vida de Rubén Darío escrita por él mismo. Caracas: Ayacucho, 1991.

Darío, Rubén (1995), "El fardo", en Azul.../Cantos de vida y esperanza. Ed. José María Martínez. Madrid: Cátedra, pp. $174-180$

\footnotetext{
${ }^{16}$ Recordemos una vez más: "En 'El fardo' triunfa la entonces en auge escuela naturalista. Acababa de conocer algunas obras de Zola, y el reflejo fue inmediato; mas no correspondiendo tal modo a mi temperamento ni a mi fantasía, no volví a incurrir en tales desvíos” (Darío, Historia de mis libros). Feliz desvío que concedió a la narrativa costumbrista una pieza nunca irrelevante.

${ }^{17}$ Con placer rindo mis agradecimientos: A Adriana Ávila por su asesoría en precisiones sintácticas y gramaticales que aquí he compendiado y simplificado; a Filiberto García Solís (q.e.p.d.) por su eficiente y amistoso servicio en la Biblioteca Samuel Ramos (Facultad de Filosofía y Letras, UNAM); al personal y recursos de la BHVP (Bibliothèque historique de la Ville de Paris).

${ }^{18}$ El epígrafe: "Sur quelques thèmes baudelairiens".

${ }^{19}$ De muy difícil acceso fuera de Nicaragua; se le cita a través de Llopesa.

${ }^{20}$ Incluye Historia de mis libros, pp. 197-225.
} 
Llopesa, Ricardo (1994), “Las fuentes de ‘El fardo’ de Rubén Darío”, Revista Hispánica Moderna, año 47, n 1 (junio de 1994), University of Pennsylvania Press: 47-55.

Disponible en: http://www.jstor.org/stable/30203372

Marasso, Arturo (1954). Rubén Darío y su creación poética. Buenos Aires: Kapeluz.

Martínez, José María (1995), “Introducción”, en Azul.../Cantos de vida y esperanza. Madrid: Cátedra, pp. 13-91.

Paredes, Alberto (2015). Las voces del relato. Madrid: Cátedra.

Rama, Angel (1977), "Prólogo", en Poesía. Caracas: Biblioteca Ayacucho, pp. IX-LII.

Valle-Castillo, Julio (2005). Cronología de Rubén Darío. Managua: La Estrella de Nicaragua.

Disponible en: http://www.estrelladenicaragua.com/rubendario.htm 